\title{
Stereotactic thalamotomy for the relief of intention tremor of multiple sclerosis
}

\author{
JD SPEELMAN, J VAN MANEN \\ From the Neurological Department, Academisch Hospital, University of Amsterdam, The Netherlands
}

SUMMARY The results of a stereotactic thalamotomy in 11 patients with clinically definite multiple sclerosis and severe intention tremor are discussed. The operation produces a beneficial effect on the tremor and an improvement of arm function in most patients. The good results have often been counterbalanced by postoperative complications or progression of the disease. An operation may be considered, if the tremor lasts for at least a year, and if there is no serious cerebral atrophy or other relevant damage to CNS structures. The patient must be capable of giving informed consent.

Good results of stereotactic thalamotomy as treatment for the intention tremor of patients with multiple sclerosis have been described..$^{1-3}$ In this report we compare our operative results with those given in the literature and discuss the effect of the thalamotomy on the course of multiple sclerosis.

\section{Patients and methods}

In the period April 1965 till February 1982 we have operated on 11 patients, five men and six women, with a severe intention tremor due to clinically definite multiple sclerosis $^{4}$ (table 1). All patients were severely disabled with a score $\geqslant 5$ on Kurtzke's disability status scale. ${ }^{5}$ At the time of the operation the disease was in a steady state and the tremor had been present for at least a year, with one exception. We then considered mental deterioration, dysphagia, (pseudo-) bulbar dysarthria, and severe cerebral atrophy a contraindication for a thalamotomy. ${ }^{8}$ The surgical technique employed was similar to that applied to relieve Parkinsonian or essential tremor, as described by Cooper, ${ }^{6}$ Guiot $^{7}$ and van Manen. ${ }^{8}$

We designed rating scales for the degree of the intention tremor (table 2) and the loss of arm function (table 3). Preoperatively, all patients had an intention tremor grade of +3 and seven patients had a loss of the arm function for the side operated on of grade +3 and four of grade +4 . Eight patients underwent a unilateral thalamotomy and three had a bilateral lesion. The postoperative follow-up period has been $\geqslant 1 \frac{1}{2}$ years (mean: $4 \frac{1}{2}$ yrs; $1 \frac{1 / 2-11}{y r s}$ )

Address for reprint requests: Dr JD Speelman, Neurological Dept, Academic Medical Centre, Meibergdreef 9,1105 AZ Amsterdam, The Netherlands.

Received 5 May 1983 and in revised form 14 October 1983. Accepted 8 November 1983 for nine patients. One patient died 3 weeks after operation and the other has been operated on 9 months before this study had been finished.

We considered an improvement of over 2 grades on the rating scale as a very good result, of 2 grades as a good result and 1 point as moderate. In case of a bilateral thalamotomy the better result of the two operations has been considered for the ultimate result. Eight patients have been interviewed on their opinion of the operation result, and this has been compared with the outcome of the rating scales. The other three patients died some years ago.

\section{Results}

The intention tremor of the arm, contralateral to the ventrolateral thalamotomy disappeared in all patients during the operation. The results of the lesion on the intention tremor and the loss of arm function scored after a postoperative interval of 3 months to 1 year, are shown in figs $2 a$ and $3 a$ and for more than $1 \frac{1 / 2}{2}$ years in figs $2 b$ and $3 b$.

For the intention tremor, eight patients have scored a good result, one patient a moderate, while no improvement has been seen in two patients. For the loss of arm function the operation produced a good result in six patients, a moderate result in three, and no improvement in two patients. The disability status scale score remained unchanged in seven patients, but became worse in four; while the functional status scale score worsened in seven patients and remained unchanged in three (fig 1). The only patient who showed an improvement in the functional status scale score died in the 3rd postoperative week.

The complications probably due to the operation are given in table 4 . Two patients had no complica- 
Table 1 Clinical data of the patients

\begin{tabular}{|c|c|c|c|c|c|c|c|}
\hline Patient & Sex & $\begin{array}{l}\text { Age at } \\
\text { 1st } \\
\text { sympt. } \\
\text { (yr) }\end{array}$ & $\begin{array}{l}\text { Interval 1st } \\
\text { sympt.-1st } \\
\text { operation } \\
(y r)\end{array}$ & $\begin{array}{l}\text { Interval tremor } \\
-1 \text { st operation } \\
\text { (yr) }\end{array}$ & Clinical symptoms before operation & $D S S^{*}$ & FSS $\dagger$ \\
\hline GvE & $\mathbf{M}$ & 28 & 8 & 6 & $\begin{array}{l}\text { INO; cerebellar syndrome: dysarthria, ataxia, intention tremor; } \\
\text { slight paresis of the legs; minimal mental deterioration }\end{array}$ & 6 & 14 \\
\hline H & $\mathbf{M}$ & 36 & 8 & 7 & $\begin{array}{l}\text { AVODS: } 6 / 60 \text {; nystagmus. cerebellar syndrome: dysarthria, } \\
\text { ataxia, intention tremor; slight pyramidal syndrome }\end{array}$ & 8 & 15 \\
\hline VN & $\mathbf{M}$ & 44 & 3 & 3 & cerebellar syndrome: dysarthria, ataxia, intention tremor & 5 & 8 \\
\hline BW & $\mathbf{F}$ & 38 & 5 & 1 & $\begin{array}{l}\text { nystagmus; cerebellar syndrome: dysarthria, intention tremor, } \\
\text { paraparesis of legs; micturition disturbances, slight impaired } \\
\text { sensory of the legs }\end{array}$ & 8 & 14 \\
\hline S & $\mathbf{F}$ & 20 & 9 & 1 & $\begin{array}{l}\text { oscillating eyes: cerebellar syndrome: dysarthria, ataxia, } \\
\text { intention tremor, slight pyramidal syndrome }\end{array}$ & 8 & 13 \\
\hline VvdW & $\mathrm{F}$ & 43 & 3 & 1 & $\begin{array}{l}\text { slight dysarthria and dysphagia; cerebellar syndrome: } \\
\text { intention tremor, pyramidal syndrome of the legs }\end{array}$ & 7 & 11 \\
\hline $\mathbf{K}$ & $\mathbf{M}$ & 31 & 3 & 2 & $\begin{array}{l}\text { INO; central scotomata; cerebellar syndrome: dysarthria, } \\
\text { intention tremor; slight pyramidal syndrome; slightly sensory } \\
\text { impairment }\end{array}$ & 7 & 13 \\
\hline DP & $F$ & 23 & 5 & 4 & $\begin{array}{l}\text { oscillating eyes; impaired vision; cerebellar syndrome: } \\
\text { dysarthria, ataxia, intention tremor; slight sensory impairment }\end{array}$ & 7 & 15 \\
\hline FS & $\mathbf{F}$ & 31 & 3 & 2 & $\begin{array}{l}\text { oscillating eyes; cerebellar syndrome: dysarthria, ataxia, } \\
\text { intention tremor; slight sensory impairment }\end{array}$ & 9 & 17 \\
\hline A & $\mathbf{M}$ & 25 & 9 & 5 & $\begin{array}{l}\text { INO; cerebellar syndrome: ataxia, intention tremor; slight } \\
\text { sensory impairment }\end{array}$ & 7 & 10 \\
\hline$S$ & $F$ & 24 & 4 & $3 / 4$ & $\begin{array}{l}\text { cerebellar syndrome: intention tremor; slight left sided } \\
\text { hemiparesis }\end{array}$ & 8 & 12 \\
\hline
\end{tabular}

*Disability Status Scale (Kurtzke ${ }^{5}$ ).

†Functional status scale (Kurtzkes).

INO = internuclear ophthalmoplegia.

AVODS = Visual activity $R$ and $\mathbf{L}$ eye

Table 2 Rating scale for severity of arm intention tremor

0 : no intention tremor

+1 : slight intention tremor: minimal impairment of arm function

+2 : moderate intention tremor: ability to keep the hand within

+3: severe intention tremor: inability to keep the hand within a distance of $15 \mathrm{~cm}$ of the intended object

Disability and functional status scale pre-and postoperative.

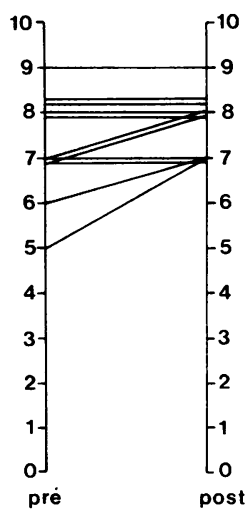

Disability status scale

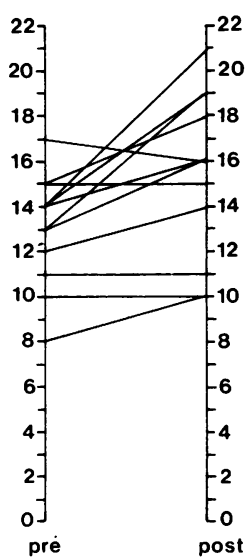

Functional status scale
Fig 1 Pre-and postoperative scores of the disability and functional status scale of Kurtzke. ${ }^{5}$ The postoperative scores have been made on the clinical data of the last postoperative examination. The higher the score the worse the disability.
Table 3 Rating scale for severity of impairment of arm function

\begin{tabular}{|c|c|}
\hline $\begin{array}{l}\text { 0: normal function } \\
+1 \text { : slight impairment: } \\
+2 \text { : moderate impairment: } \\
\text { +3: severe impairment: }\end{array}$ & $\begin{array}{l}\text { handwriting is legible } \\
\text { can take hold of an object: } \\
\text { able to operate an electric } \\
\text { wheelchair; able to eat unaided } \\
\text { no functional use of the arm: } \\
\text { able to keep the arm extended } \\
\text { with(out) postural tremor }\end{array}$ \\
\hline
\end{tabular}

4: no control of the arm
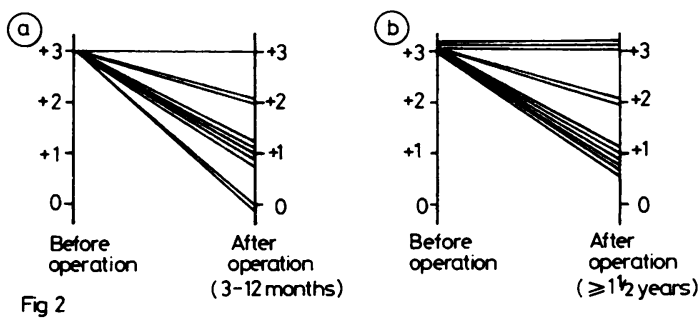

Fig 2 The severity of the intention tremor has been expressed in a scale from 0 to +3 (see table 2).

Preoperatively, all patients had a severity of intention tremor of grade +3. (a) shows for the period 3 months to 1 year after the thalamotomy, a disappearance of the tremor 2 cases, an improvement of the severity of the tremor 7 , but a failure for 1 . (b) gives the results of 11 thalamotomies $(9$ patients), $\geqslant 1 \frac{1 / 2}{\text { years postoperatively. There is an }}$ improvement of the tremor in 8 cases, but a failure in 3 . 
(a)

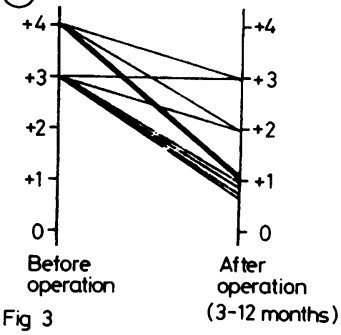

(b)

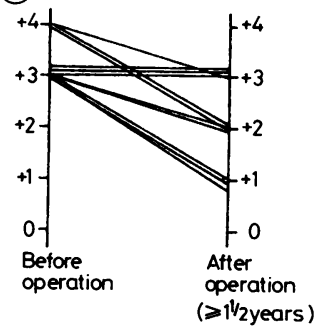

Fig 3 The severity of the impairment of arm function has been expressed in a scale from 0 to +4 (see table 3). (a) shows the results after 3 months to 1 year for 10 thalamotomies (8 patients). The patients with a preoperative score of +4 , all improved. For the patients with an impairment score of +3 one operation failed, but 5 gave an improvement (with 2 grades in 4 patients and 1 grade in 1 ).

(b) gives the results of 11 operations ( 9 patients), $\geqslant 1 \frac{112}{2}$ year postoperatively. Of the patients with a preoperative impairment score of +4 , all 3 operations gave an improvement. For the group with a score of +3 , preoperatively, 5 operations gave an improvement, but 3 none.

Table 4 Complications due to thalamotomy

\begin{tabular}{|c|c|c|}
\hline $\begin{array}{l}\text { Somnolence } \\
\text { Frontal lobe syndrome } \\
\text { Speech disorders }\end{array}$ & $\begin{array}{l}\text { for a few days } \\
\text { for a few weeks } \\
\text { for } 2 \text { months } \\
\text { for a few days } \\
\text { permanent }\end{array}$ & $\begin{array}{l}1 \text { patient } \\
1 \text { patient } \\
1 \text { patient } \\
3 \text { patients } \\
1 \text { patient }\end{array}$ \\
\hline $\begin{array}{l}\text { Fixed gaze to side of } \\
\text { operation }\end{array}$ & for 3 weeks & 1 patient \\
\hline Hemiparesis & $\begin{array}{l}\text { for a few days } \\
\text { permanent }\end{array}$ & $\begin{array}{l}3 \text { patients } \\
4 \text { patients }\end{array}$ \\
\hline $\begin{array}{l}\text { Slight hemihypaesthesia } \\
\text { Micturition disturbances }\end{array}$ & $\begin{array}{l}\text { permanent } \\
\text { transient } \\
\text { permanent }\end{array}$ & $\begin{array}{l}1 \text { patient } \\
1 \text { patient } \\
2 \text { patients }\end{array}$ \\
\hline
\end{tabular}

Table 5 Opinion of 8 patients concerning the results of the operation

\begin{tabular}{ll}
\hline Enthusiastic: & none \\
Satisfied: & 2 patients \\
Moderate positive: & 2 patients \\
Negative: & 4 patients \\
\hline
\end{tabular}

Table 6 Comparison of the objective effect of the operation with the opinion about the results of 8 patients

\begin{tabular}{llll}
\hline Opinion & \multicolumn{3}{l}{ Operation result } \\
\cline { 2 - 4 } & Good & Moderate & None \\
\hline Satisfied & 1 & 1 & - \\
Moderate positive & 2 & $\frac{1}{1 *}$ & - \\
\hline Negative & $3^{*}$ & $1^{*}$ & \\
\hline
\end{tabular}

${ }^{*} 1$ patient with bilateral thalamotomy.

tions and three patients had transient symptoms only. Three patients died many years after the operation, but the fourth patient died 3 weeks postoperatively of an aspiration pneumonia. For the opinion of eight patients concerning the results of the operation, see table 5. Comparison of the result of the interview of the eight patients with the outcome of their rating scale scores is shown in table 6 .

\section{Discussion}

Stereotactic thalamotomy had in most cases a favourable effect on the intention tremor of multiple sclerosis patients. Our results agree with those of others (table 7). Improvement of arm function by the operation has not been clearly recorded in the literature. According to Riechert and Richter ${ }^{3}$ twothirds of their patients operated on were able to eat by themselves, and $50 \%$ showed an improvement of their handwriting. ${ }^{3}$ Arsalo et al reported that $50 \%$ of their operated patients showed an improvement of arm function. ${ }^{2}$

However, the operation did not improve disability or the functional status scale of Kurtzke in our patients; a number of patients deteriorated. One of the reasons for this is that intention tremor has been noted in these scales only as part of the cerebellar syndrome.

The number of patients with transient or permanent neurological complications due to the operation, and their severity, was notably higher than in patients operated upon for Parkinsonian and essential tremor. ${ }^{3}$ Our patients already had multiple lesions in the nervous system. The operation added a new lesion with further neuronal disturbance.

Table 7 Comparison of our results of thalamotomy with those in literature

\begin{tabular}{|c|c|c|c|c|c|}
\hline \multirow[t]{2}{*}{ Authors } & \multirow[t]{2}{*}{ Number of patients } & \multicolumn{4}{|c|}{ Operation results } \\
\hline & & Very good & Good & Moderate & None \\
\hline $\begin{array}{l}\text { Cooper' } \\
\text { Riechert, Richter } \\
\text { Arsalo et al }{ }^{2} \\
\text { Mundinger } \\
\text { Speelman, van Manen }\end{array}$ & $\begin{array}{l}32 \\
29 \\
26 \\
? \\
11\end{array}$ & $\begin{array}{l}72 \% \\
65 \cdot 5 \% \\
73 \% \\
17 \% \\
-\end{array}$ & $\begin{array}{l}23 \% \\
20.6 \% \\
19 \% \\
65 \% \\
8 \text { pat. }(73 \%)\end{array}$ & $\begin{array}{l}\overline{10} \cdot 3 \% \\
-3 \% \\
1 \text { pat. }(9 \%)\end{array}$ & $\begin{array}{l}5 \% \\
3 \% \\
8 \% \\
5 \% \\
2 \text { pat. }(18 \%)\end{array}$ \\
\hline
\end{tabular}


Of the eight patients interviewed four had a negative opinion of the results of the operation. One patient had a recurrence of tremor, but the other three had a favourable outcome according to the rating scales. One of these had micturition disturbances, a second a severe dysarthria, and the third expected to be cured of multiple sclerosis by the operation. It is clear that a good operation result, with an improvement of the tremor and recovery of arm function can be nullified by a deterioration of other neuronal systems. This can be caused by the operation, owing to a misplaced lesion, the interaction of the thalamic lesion with neuronal disturbances by multiple sclerosis plaques, or the provocation of a relapse of multiple sclerosis. ${ }^{10}$ But it also could be the natural course of the disease.

It is clear that stereotactic thalamotomy is a symptomatic treatment for the relief of intention tremor only. The operation does not influence the course of multiple sclerosis in a positive way. The result is often nullified because of complications of the operation, a progressive course of the disease, or the false hope of the patient. We are reluctant to perform a bilateral thalamotomy, despite favourable reports by others. In our opinion, this operation can be considered as a symptomatic treatment for a patient with multiple sclerosis and a disabling intention tremor, which has been present for at least a year. Severe damage of other neuronal systems, mental deterioration, and definite cerebral atrophy are considered as contraindications. It is important that the patient must be informed of what may be expected of the operation, and what are the risks involved. It has become clear that despite this preparation, most of our patients still have expected too much of the thalamotomy.

\section{References}

' Cooper IS. Relief of intention tremor of multiple sclerosis by thalamic surgery. JAMA 1967;199:68994.

${ }^{2}$ Arsalo A, Hänninen A, Laitiken L. Functional neurosurgery in the treatment of multiple sclerosis. Ann Clin Res 1973;5:74-9.

${ }^{3}$ Riechert T, Richter D. Stereotaktische Operationen zur Behandlung des Tremors der Multipele Sklerose. Schw Arch Neurol Neurochir Psychiat 1972;111: 411-6.

${ }^{4}$ McDonald WI, Halliday AW. Diagnosis and classification of multiple sclerosis. $\mathrm{Br}$ Med Bull 1977;33:4-8.

${ }^{5}$ Kurtzke JF. Further notes on disability evaluation in multiple sclerosis with scale modifications. Neurology (Minneap) 1965;15:654-61.

- Cooper IS. Neurosurgical alleviation of intention tremor of multiple sclerosis and cerebellar disease. New Engl J Med 1960;263:441-4.

' Guiot G, Brion S, Fardeau M, Bettaïel A, Molina P. Dyskinésie volitionelle d'attitude supprimée par la coagulation thalamo-capsulaire. Rev Neurol (Paris) 1960; 102:220-9.

${ }^{8}$ Van Manen J. Stereotactic methods and their applications in disorders of the motor system. Thesis. Van Gorcum, Assen, Neth. 1967

${ }^{9}$ Mundinger F. Stereotaktische Operationen am Gehirn: Grundlagen, Indikationen, Resultaten. Stuttgart: Hippokrates Verlag, 1975.

${ }^{10}$ Riechert T, Hassler R, Mundinger F, Bronisch F, Schmidt H. Pathologic Anatomical findings and cerebral localization in stereotactic treatment of extrapyramidal motor disturbances in multiple sclerosis. Confin Neurol 1975;37:24-40. 